\title{
Aplicación de Rizobacterias que promueven el crecimiento en plantas (PGPR) del género Pseudomonas spp como controladores biológicos de insectos y nemátodos-plagas
}

\section{Applying Plant Growth Promoting Rizobacteria (PGPR) of the Genus Pseudomonas ssp as Biological Controllers of Insects and Plague Nematodes}

\author{
${ }^{\bullet}$ Hayron Canchignia Martínez ${ }^{1}$, Nicolás Cruz Rosero ${ }^{1,2}$, Alexandra Barrera Álvarez ${ }^{3}$, \\ Jaime Morante Carriel ${ }^{1,2}$, Gina Canchignia Malagón ${ }^{1}$, María Peñafiel Jaramillo ${ }^{2}$ \\ ${ }^{1}$ Área de Microbiología del Departamento de Biotecnología, Facultad de Ciencias Agrarías, Universidad Técnica Estatal de \\ Quevedo, Campus Ing. Manuel Haz Álvarez, km 1.5 vía a Santo Domingo de los Tsáchilas. EC.120501. Quevedo, Ecuador. \\ hcanchignia@uteq.edu.ec; vane_canchignia@hotmail.com \\ ${ }^{2}$ Facultad de Ciencias Ambientales, Universidad Técnica Estatal de Quevedo, Campus Ing. Manuel Haz Álvarez, km 1.5 vía a \\ Santo Domingo de los Tsáchilas.EC.120501.Quevedo,Ecuador.jcruz@uteq.edu.ec; jmorante@uteq.edu.ec; \\ ${ }^{3}$ Facultad de Ciencias Pecuarias, Campus Finca Experimental "La María” km 7 vía Quevedo-El Empalme. \\ Universidad Técnica Estatal de Quevedo. EC.120501.Quevedo, Ecuador. barreraalvarez@yahoo.com
}

\begin{abstract}
Resumen
T as rizobacterias son una alternativa que ha demostrado no generar resistencia en los fitopatógenos. Cepas de Pseudomonas cumplen un rol importante en el biocontrol, por su amplia diversidad de compuestos bioactivos hacia el control de patógenos de plantas. La información obtenida se enfocó al estudio de aislados de Pseudomonas spp que tienen la capacidad de disminuir la viabilidad de agentes patógenos como: hongos, bacterias, nematodos, mediante un mecanismo antagonista y de inducir los sistemas de defensa de plantas por la resistencia sistémica adquirida (RSA) y resistencia sistémica inducida (RSI).
\end{abstract}

Palabras clave: Rizobacterias, fitohormonas, Resistencia sistémica adquirida, Resistencia sistémica inducida.

\section{Abstract}

D are an alternative that has proven not to generate Rresistance in pathogens. Pseudomonas strains play an important role in biocontrol, because they provide a great variety of bioactive compounds to control plant pathogens. The information search focused on the study of Pseudomonas spp isolates which have the ability to diminish the viability of such pathogens as: fungi, bacteria, nematodes through the use of an antagonist mechanism inducing plant defense systems through systemic acquired resistance (SAR) and induced systemic resistance (ISR).

Key words: Rhizobacteria, phytohormones, systemic acquired resistance, induced systemic resistance.

\section{Introducción}

E xisten suelos con una amplia diversidad de bacterias benéficas que mantienen el rendimiento en los cultivos. Dentro de este grupo de microorganismo, se destacan las rizobacterias no patogénicas del género Pseudomonas (Sacherer et al., 1994). Estas bacterias existen en forma libre en la rizosfera o pueden estar asociados en la superficie de las raíces (Fukui et al.,
1994). Las rizobacterias promueven el crecimiento de la planta (PGPR), tienen la disponibilidad de colonizar las raíces y estimular el crecimiento de la planta. La actividad de PGPR ha sido reportada por cepas de muchos géneros como: Azoarcus, Azospirillum, Azotobacter, Arthrobacter, Bacillus, Clostridium, Enterobacter, Gluconoacetobacter, Pseudomonas y

Recibido: 30-septiembre-2014. Recibido en forma corregida: 20-noviembre-2014. Aceptado: 26-marzo-2015. Publicado como ARTÍCULO DE REVISIÓN en Ciencia y Tecnología 8(1): 25-35 Junio de 2015 
Serratia (Somers et al., 2004).

Las plantas están expuestas a un sin número de patógenos en su medio natural, como parte de su proceso evolutivo han desarrollado múltiples y complejas estrategias de defensa, permitiendo adaptarse a diferentes entornos ambientales y defenderse del ataque a patógenos. Para contrarrestar este ataque, ellas desarrollan varios mecanismos de respuestas a defensa, incluye las barreras pre-existentes físicas y químicas, así como respuestas inducibles que son activadas antes y después de la percepción del patógeno (HammondKosack y Jones, 1996).

La presencia de nematodos en cultivos susceptibles $\mathrm{y}$ en equilibrio con las rizobacterias, ha permitido mantener estos sistemas de producción durante varios años sin presentar una reducción en su rendimiento. Rizobacterias del género de Pseudomonas spp., y Bacillus spp., son empleadas como agentes de biocontrol de diversos nematodos. Las rizobacterias promueven el crecimiento de plantas y previenen el establecimiento de patógenos. Además, desencadenan una serie de reacciones de defensa en la planta hospedera (Pieterse y Van Loon, 1999).

El patógeno al entrar en contacto con la planta, pone en marcha un sistema de comunicación molecular entre ambos, que desencadena la inducción de mecanismo de defensa en la planta, que está activando la Resistencia Sistémica Adquirida (RSA) (Desender et al., 2007). La activación del mecanismo de defensa por bacterias no patogénicas, Verhagen et al. (2004), manifiestan que la Resistencia Sistémica Inducida (RSI) proporciona a la planta mejor capacidad de respuesta y frente eficientemente a una infección por patógenos.

\section{Respuesta defensivas sistémicas en plantas}

Los mecanismos de Resistencia Local Adquirida (RLA), se activan en tejidos alejados por señales o mensajes que regulan la activación de reacciones defensivas en zonas no infectadas en la planta. Este tipo de reconocimiento inicia una definida cascada de transducción de señales. La célula de la planta infectada dirige una generación de componentes de señalización endógenos y biosíntesis subsecuentes de proteínas antimicrobianas locales. También, sistemáticamente en distintas partes de la planta se produce un fenómeno denominado RSA (Ryals et al., 1996).

La resistencia sistémica es un estado fisiológico que mejora la capacidad defensiva, elicitado por estímulos específicos medio-ambientales. Las defensas innatas de las plantas son potenciadas hacia subsecuentes desafíos bióticos. Este estado mejorado de resistencia es efectivo en un amplio rango de patógenos: hongos, bacterias, virus, nematodos, plantas parasitas e insectos herbívoros. Existen dos formas definidas de respuestas sistémicas RSA y RSI, que se diferencian en el tipo del elicitor y las vías regulatorias involucradas por Ácido Salicílico (AS), Ácido Jasmónico (AJ) y Etileno (ET) (Van Loon et al., 1998).

La respuesta defensivas RSA es inducida por patógenos, debido a un incremento de AS sintetizado endógenamente en la planta, siendo ésta molécula de señalización esencial en la vía de RSA (Métraux et al., 1990). La acumulación de AS parece ser crítico para la inducción de la vía de señalización RSA, porque en plantas transgénicas NahG inhábiles de acumular AS son incapaces de desarrollar RSA (Gaffney et al., 1993). La infección de una planta por un patógeno biotrófico activa la respuesta defensiva general. Esta forma de resistencia inducida se conoce como RSA (Ryals et al., 1996). Esto desencadena una resistencia sistémica y duradera e inespecífica para un amplio rango de patógenos (Sticher et al., 1997), induciendo la expresión de genes característicos para RSA, actuando a nivel local o sistémicamente.

En plantas al activarse RSA por el ataque del patógeno se sintetizan proteínas de defensa que pertenece a la familia de proteínas de defensas (PR). Las proteínas PR se sintetizan y se acumulan en los tejidos de las plantas en situaciones de infección por diferente tipo de patógenos: (virus, bacterias y hongos) o en situaciones relacionadas, como heridas (asociadas al ataque por depredadores) (Nimchuk et al., 2003). Las proteínas PR-1 presentan una actividad antifúngica (fitoalexinas). Las PR-2 tienen actividad $\beta-1,3$ glucanasa. La PR-5 se expresa como taumatina, inducida por infección viral, fúngica y heridas (Moreno, 2006). La infección por nematodos Meloidogyne incognita induce el aumento de la actividad glucanasa y quitinasa en pepino, por contribución de proteínas PR a la protección de nematodos parasíticos (Zinovèva et al., 2001).

\section{Respuestas sistémicas dependientes del jasmonato/ etileno (JA/ET), RSI}

El jasmonato de metilo (MeJA) está directamente implicado en la respuesta defensiva de las plantas frente a patógenos biotróficos (Devoto et al., 2005). La colonización de raíces por cepas no patogénicas PGPR, dan paso a RSI, siendo esta efectiva contra el ataque de patógenos, donde son combatidos a través de un mecanismo de defensa dependiente ha JA/ET (Ton et al., 2002). En trabajos experimentales se ha demostrado que esta resistencia se induce tras la colonización de raíces por bacterias del género Pseudomonas spp y confiere la protección a niveles sistémicos en tejidos alejados, conformando RSI (Pieterse et al., 1999). Este fenómeno no es exclusivo de Arabidopsis, sino que también se ha demostrado en otras especies vegetales, 
como: tabaco, tomate, pepino y rábano (Iavicoli et al., 2003). Rizobacterias no patógenas de P. fluorescens CHA0, P. fluorescens WCS417 y P. aeruginosa 7NSK2 reducen el daño en los tejido, por la inducción de la RSI, por la acumulación de fitoalexinas (resveratrol y viniferina) en células de Vitis vinifera frente a Botrytis cinerea (Verhagen et al., 2009).

El mecanismo de respuesta para el gen de tipo Npr1 es dependiente de la ruta de AS. Van der Ent et al. (2009), manifiesta que la colonización en raíces de Arabidopsis por P. fluorescens WCS417r dirigen la RSI, activando un factor de transcripción MYB72 adquiriendo una cascada de transducción de señales que están activando NPR1.

Ambos mecanismo de respuesta por RSI y RSA son efectivos hacia un amplio rango de patógenos. Sin embargo, estos son diferenciados en la efectividad de los componentes de señalización involucrados hacia diferentes tipos de patógenos. Además RSA y RSI están caracterizados por un estado fisiológico único llamado “imprimación” (Figura 1). La imprimación en plantas juega una activación rápida y fuerte de las respuestas de defensas antes y después de ser sometido al patógeno (Conrath et al., 2006).

\section{Sistemas defensivos interacción planta-patógeno}

La barrera física es un mecanismo de defensas en plantas, al ataque de agentes patógenos. La pared celular o la cutícula dificultan la entrada de diferentes agentes invasores, e impiden el ingreso del patógeno al citoplasma celular y sus nutrientes (Figura 2) siendo este mecanismo particularmente notable para el control de patógenos biotróficos (Mauch-Mani y Slusarenko, 1993). Las barreras químicas presenta un mecanismo de defensa más sofisticado, involucra cambios bioquímicos, está defensa es inducida después de la detección de un microorganismo patogénico por la vía de reconocimiento, realizada por una molécula elicitora durante la interacción planta-patógeno (Ebel y Cosio, 1994). Durante esta interacción, la planta puede
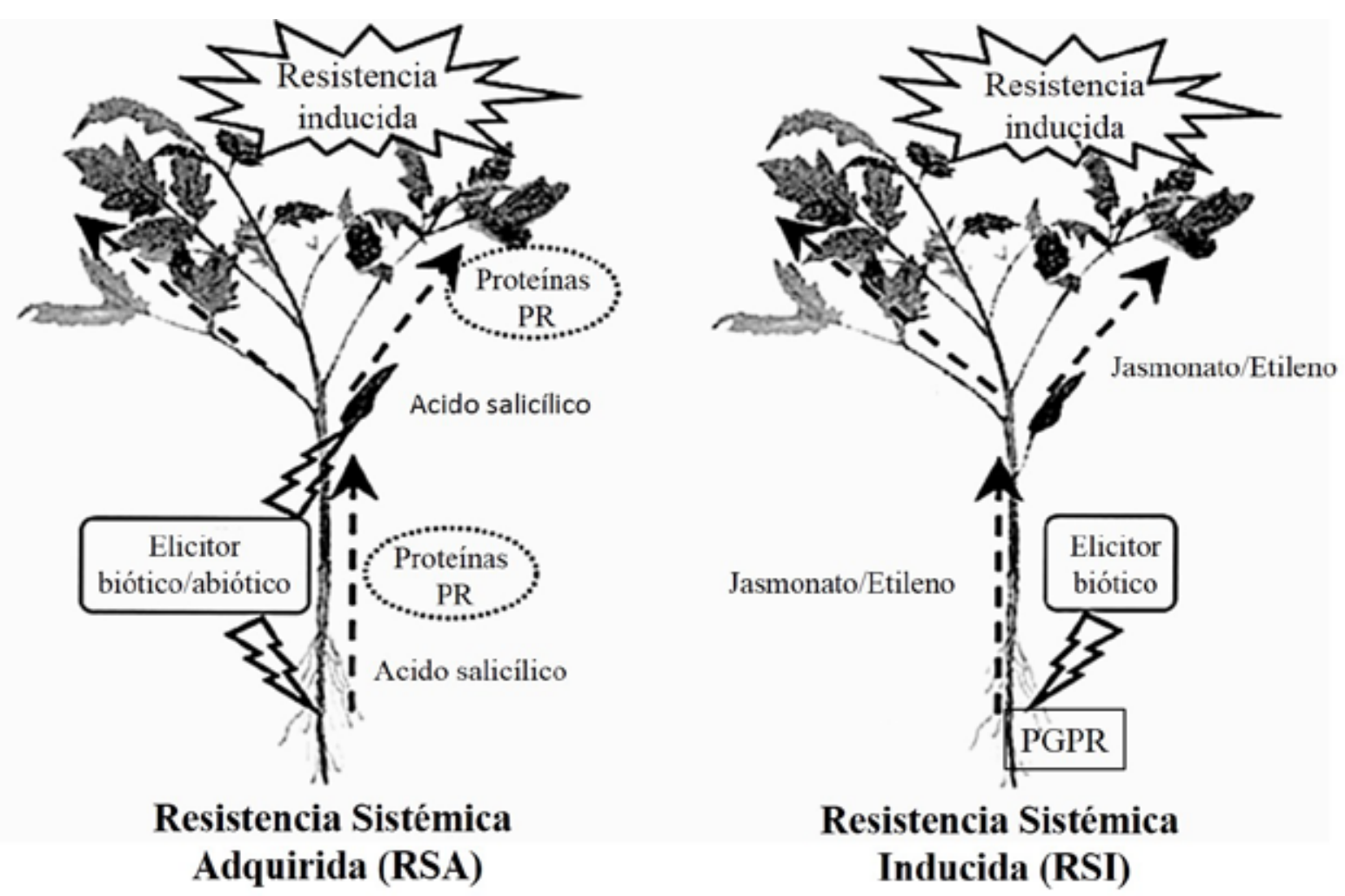

Figura 1. Modelo de la resistencia sistémica en plantas. La resistencia sistémica RSA, es inducida por elicitores abióticos o bióticos en raíz o tejido foliar, dependiente de la fitohormona AS y asociado con la acumulación de proteínas PR. RSI, inducida por la exposición de las raíces a cepas especificas PGPR es dependiente de fitohormonas ET /JA, no está asociado con la acumulación de proteínas PR. Sin embargo, ambas respuestas están entrelazadas molecularmente, está demostrado por su dependencia en una versión funcional del gen NPR1 en Arabidopsis thaliana (Vallad y Goodman, 2004) 

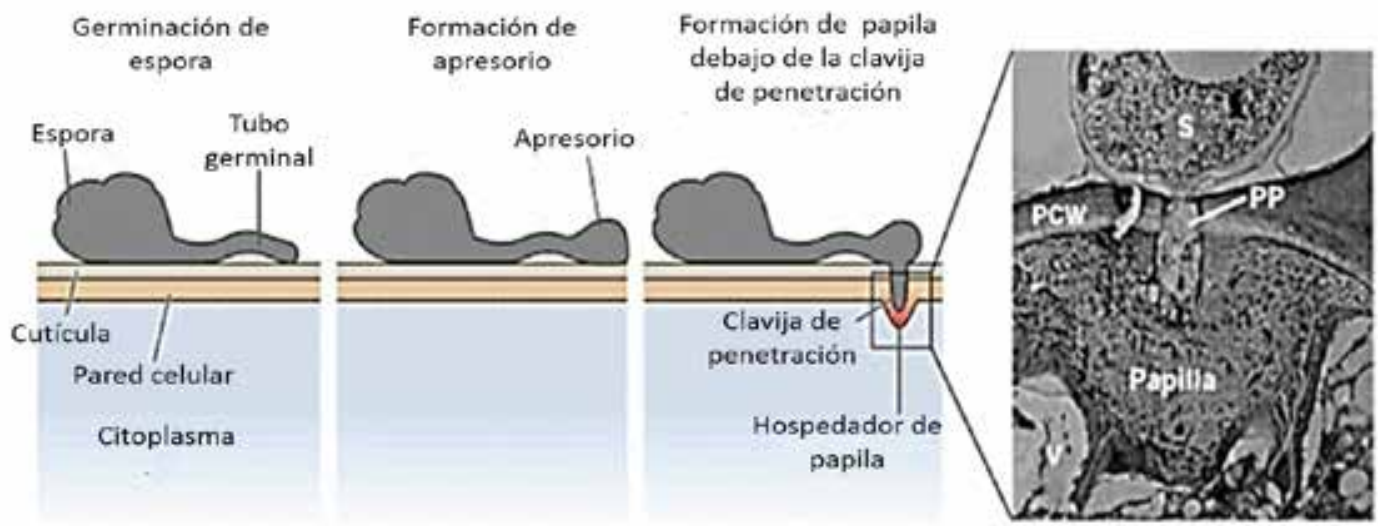

Figura 2. Fortificación de la pared celular o cutícula. La formación de papila está compuesta por materiales de lignina o callosa que actúan como barreras físicas (Mauch-Mani y Slusarenko 1993)

sintetizar fitoalexinas, incrementar el fortalecimiento de la pared celular y la producción de proteínas antifúngicas (Jackson y Taylor, 1996). Esto comprende la acumulación de fitoalexinas sintetizadas por la planta, que permiten la deposición de componentes fenólicos, lignina $\mathrm{o}$ materiales cómo callosa. Incrementa la actividad de las proteínas relacionadas con la patogénesis con actividad hidrolítica (quitinasas y glucanasas) y respuesta de hipersensibilidad (HR), estas reacciones reducen el crecimiento del patógeno (Figura 3) (Trouvelot et al., 2008).

La acumulación de fitoalexinas, como respuesta defensiva incluye: la síntesis de proteínas, compuestos fenólicos que refuerzan la pared celular y la producción de un conjunto de proteínas denominadas PRs. Cabe indicar, que éstas son proteínas de defensa, con una función distinta a las proteínas R; son elementos que actúan en la percepción del patógeno y génesis de señal, que mediante una serie de iones, moléculas y dispositivos celulares, es convertida y trasmitida (transducción) en una orden de activación de respuesta (Conejero, 1996).

La resistencia en plantas es acompañada por una muerte celular rápida localizable y programada al

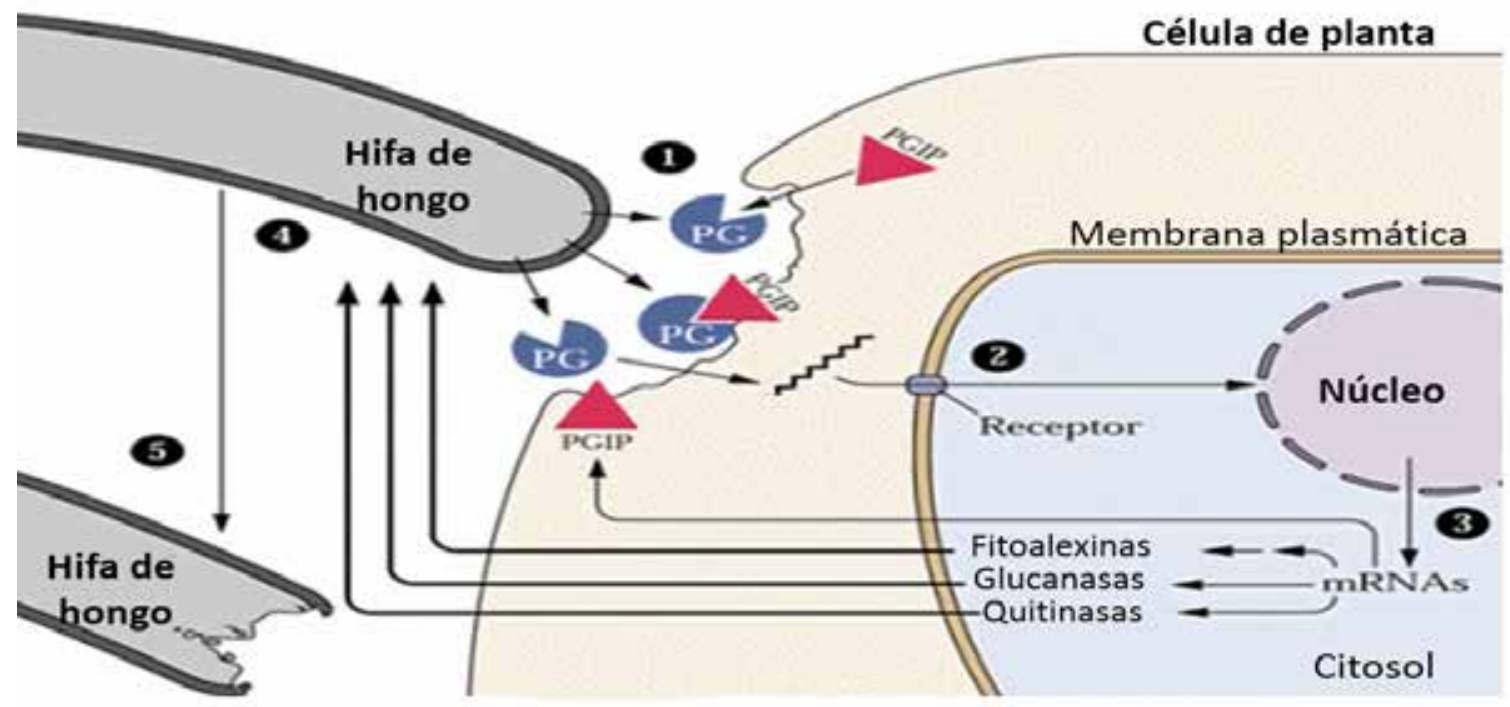

Figura 3. Síntesis de proteínas de inhibición a poligalacturonasas (PGIPs) que inhiben a endopoligalacturonasas presentes en hongos necrótrofos. 1) Reconocimiento de poligalacturonasas. 2) Proteínas receptores nucleares para activación de genes de defensa. 3) Activación de genes de defensa. 4) Producción de fitoalexinas, glucanasas y quitinasas. 5) Daño de pared celular del hongo (Trouvelot et al., 2008) 
sitio de infección por el patógeno, conocido como respuesta hipersensibilidad (RH). Esto precede a disturbio fisiológico (flujo de iones, cambios de $\mathrm{pH}$, defosforilación de membrana), activando mecanismos sofisticados en plantas para detener el avance de patógenos biotróficos. La respuesta defensiva puede ser también de tipo compatible, no tiene lugar a la muerte celular por $\mathrm{RH}$, pero se activan una batería de señales que también pueden ser liberadas frente a estrés de naturaleza biótica o abiótica. En las interacciones compatibles, la enfermedad se extiende a toda la planta (Nurnberger y Scheel, 2001).

Las fitoalexinas son compuesto antimicrobianas de bajo peso molecular, estas fueron las primeras respuestas moleculares conocidas por las plantas (Ryals et al., 1996). Los diferentes mecanismos de defensa de la planta frente al patógeno, se describe en base a un esquema adaptado de Conejero (1997) (Figura 4), la respuesta defensiva en plantas se caracteriza por ser de naturaleza multi-componente con la producción: a) Enzimas implicadas en la biosíntesis de compuestos antimicrobianos de lignina $y$ fitoalexinas. b) Acumulación de proteínas que frenan la expansión del patógeno por glucanasas y quitinasas.

\section{Estrategias de reconocimiento plantapatógeno}

Reconocimiento inespecífico. Los patógenos tienen diversas estrategias de ataque hacia la planta para poder colonizarla: a) Hongos y bacterias fitopatógenas entran a través de los estomas, de poros acuosos o heridas y proliferan en los espacios intercelulares. b) Los hongos además pueden entrar directamente a través de las células epidérmicas, extender sus hifas en la superficie de las células. Sin embargo, estos microorganismos liberan factores de virulencia en las células vegetales, para crear un entorno favorable de su proliferación en la planta (Jones y Dangl, 2006).

El patógeno al estar en contacto con la planta, desencadena un sistema de comunicación molecular entre ambos, con la inducción de mecanismo de defensa en la planta(Desender et al., 2007). Los PAMPs (Patrones Moleculares Asociados-Patógenos), son moléculas producidas por el patógeno o huésped, en fase inicial, induciendo la respuesta defensiva en la planta (Mackey y McFall, 2006). Los PAMPs, son elicitores generales implicadas en la inmunidad no especifica y asociada a resistencia, para un amplio rango de patógenos (Jones y Dangl, 2006; Bent y Mackey, 2007).

Los PAMPs en las células vegetales son reconocidos por receptores transmembrana no específicos PRRs (Receptores de patrones reconocimiento), desencadenan varios cambios en las células como: a) Variaciones en el potencial de membrana. b) Producción de Especies Reactivas de Oxigeno (ROS). c) Peroxidación de lípidos y fosforilación de proteínas. Estos alteran la fisiología celular y generan mensajeros químicos implicados en la activación de la resistencia local o sistémica (Desender et al., 2007). Los mecanismos de defensa activados por PAMPs, incluyen el refuerzo de la pared celular, mediante deposición de callosa y lignina.

Reconocimiento específico. Los microorganismos son capaces de sintetizar "efectores", factores de avirulencia (Avr), que superan la resistencia inespecífica por PAMPs

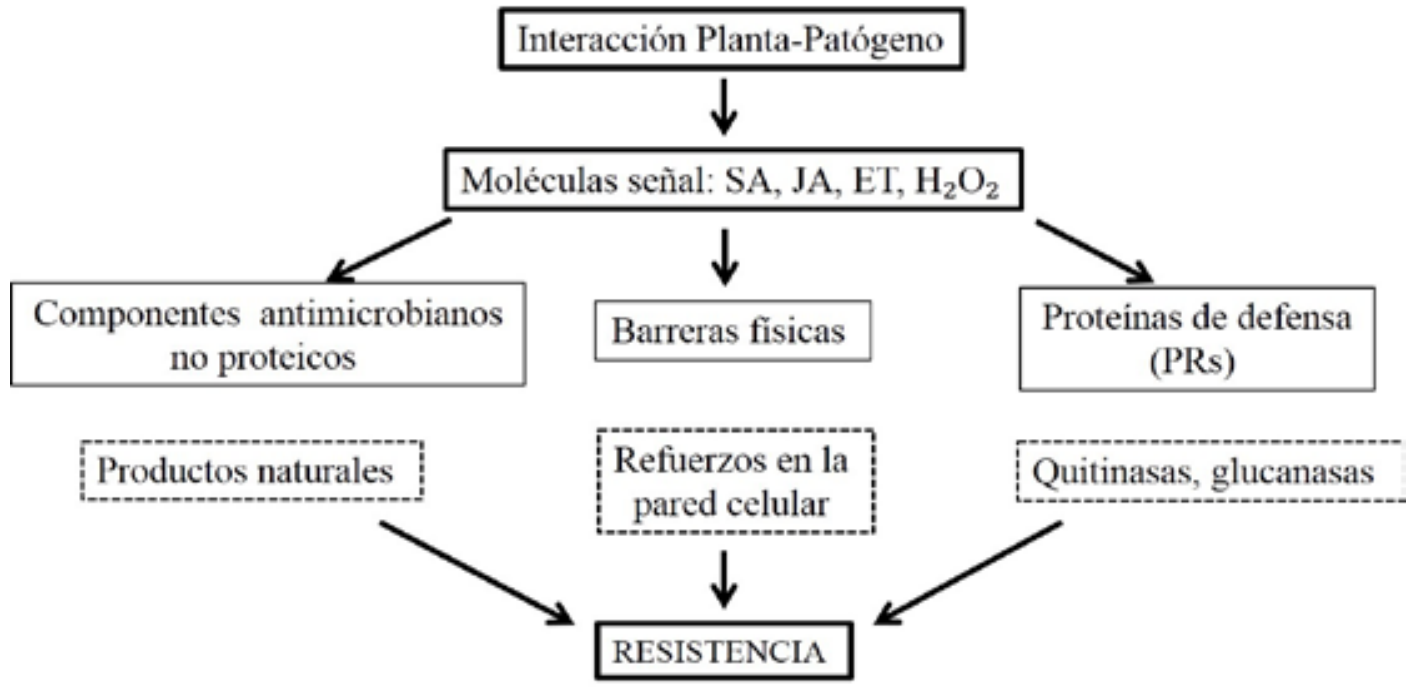

Figura 4. Respuesta defensiva de la planta de naturaleza multicomponente. Interacción planta - patógeno, activando moléculas de señalización: AS, ácido salicílico; JA, ácido jasmónico; ET, etileno; $\mathrm{H}_{2} \mathrm{O}_{2}$, peróxido dihidrógeno. Adaptado de Conejero (1997) 
en plantas. La respuesta inmune es iniciada cuando un producto del gen de resistencia $\mathrm{R}$, directamente o indirectamente reconoce las moléculas "efectores" a proteínas producidas por genes de avirulencia (Avr) del patógeno. Estos tienen la capacidad de unión a nucleótidos (NB) y porque poseen dominios repetidos ricos en el aminoácido Leucina (LRR). Al no existir el correspondiente gen de resistencia $\mathrm{R}$ a estos efectores, la infección se extenderá a toda la planta, conocida como interacción incompatible. El efector patogénico al ser reconocido de forma específica por una proteína NB-LRR, permite una interacción de tipo compatible, que normalmente va asociada a la muerte celular programada o HR (Martin et al., 2003).

La expresión del gen (RK) a nematodos agallador, activa la resistencia en el frijol CB46 y los mecanismos de $\mathrm{HR}$, inicia con una rápida y localizable muerte celular del tejido radicular, impidiendo la formación de un sitio de alimentación y desarrollo del nemátodo $M$. incognita (Das et al., 2008). La expresión del gen $\mathrm{H} 1$ le confiere resistencia hacia el nematodo de Globodera rostochiensis en papa, donde la expresión de este gen $\mathrm{H} 1$ da como resultado una clara respuesta HR alrededor de nematodos juveniles (Williamson, 1999).

\section{Rizobacterias productoras de metabolitos secundarios con actividad antagonista}

Al control biológico por el empleo microorganismos o subproductos son capaces de actuar contra: bacterias, hongos y nematodos depredadores. Alternativas del uso de microorganismos, para el control de enfermedades de plantas y de otros problemas microbiológicos que limitan la productividad en los cultivos. La aplicación de rizobacterias del género Bacillus subtilis y Pseudomonas fluorescens, se consideran bacterias eficientes para controlar enfermedades foliares y radiculares (Cook, 1989; Atlas, 2002). Además, estas rizobacterias exhiben un amplio rango de habilidades fisiológicas, que le permiten vivir en una alta diversidad de hábitats: desiertos, aguas termales y suelos árticos (Atlas, 2002). Diversas cepas de Pseudomonas poseen una actividad biocontroladora y promueven el crecimiento en plantas. Las PGPR tienen la capacidad de inducir el sistema de respuesta de defensa en plantas o la capacidad de actuar sobre el patógeno (Preston, 2004).

Las PGPR proveen diferentes mecanismos de defensa para la supresión de enfermedades provocadas por los patógenos en plantas, esto incluye la competencia por nutrientes, espacio y producción de antibióticos: pioluteorina (Plt), pirrolnitrina (Prn), ácido fenazina1-carboxilico (PCA) y 2,4- diacetilfloroglucinol $(2,4$ DAPG). La producción de sideróforos (pigmento verde amarillento fluorescente), pseudobactina que limita la disponibilidad de hierro necesario para el crecimiento de patógenos. Otro importante mecanismo incluye la producción de enzimas líticas como: quitinasas y $\beta$-1,3glucanasas que degradan la quitina y glucanos presentes en la pared celular del hongo, producción de ácido cianhídrico (HCN) (Ramamoorthy et al., 2002).

Los antibióticos como: Plt, Prn, PCA y 2,4 DAPG son los principales controladores biológicos de hongos y bacterias. Por aislamientos directos de estos y la identificación por técnicas moleculares se ha demostrado que estos antibióticos son producidos por las bacterias en la rizósfera y desempeñan un rol en la supresión de patógenos de plantas en el suelo (Raaijmakers et al., 1997). El antibiótico de amplio espectro 2,4DAPG es producido por $P$. fluorescens CHA0 y tiene propiedades anti-fúngicos, anti-bacterianos, actividades anti-helmínticas y fitotóxicas. También estimula la resistencia sistémica inducida en plantas al interaccionar con las raíces de la planta (Dwivedi y Johri, 2003). Las actividades anti-fúngicas como: 2,4-DAPG, Plt y Prn están involucradas en las interacciones antagonistas y supresión de enfermedades Fusarium oxysporum, Phytophthora cinnamoni, Thielaviopsis basicola (Haas y Défago, 2005).

\section{La resistencia sistémica inducida por PGPR hacia problemas fitopatológicos}

En el sector agrícola el cultivo de Dianthus caryophillus (claveles) bajo la aplicación de $P$. fluorescens WCS417 protege sistémicamente frente a Fusarium oxysporum que provoca la marchitez de la planta (Van Peer et al., 1991). Las semillas de pepino tratadas con PGPR, P. putida 34-13 y P. fluorescens 68-4, significativamente reduce la enfermedad de antracnosis causada por Colletotrichum orbiculare (Wei et al., 1991).

La aplicación de $P$. fluorescens $\mathrm{CHA} 0$ al suelo provee la resistencia sistémica inducida frente a la inoculación con el virus de necrosis en tabaco (TNV) (Maurhofer et al., 1994). El tratamiento de semillas de arroz, raíces en inmersión y aspersión foliar con $P$. fluorescens cepas Pf1 y Fp7, demuestra una alta inducción de RSI hacia el patógeno del tizón de la vaina, Rhizoctonia solani (Vidhyasekaran y Muthamilan, 1999).

\section{Aplicación de PGPR como biocontroladores frente a insectos-plagas}

Las PGPR del género Pseudomonas spp como controladores biológicos de insectos-plagas, influyen en el crecimiento y etapas del desarrollo de insectos. Pseudomonas maltophila afecta el crecimiento del estadio larval de Helicoverpa zea, gusano elotero del maíz, dirigiendo una reducción del $60 \%$, de la emergencia de etapa adulta, mientras larvas que emerjan desde pupas infectadas con la bacteria son 
más pequeños (Bong y Sikorowski, 1991). El ritmo de consumo y digestibilidad del alimento por Helicoverpa armigera se ve afectada, al alimentarse de plantas de algodón tratadas con Pseudomonas gladioli, por el incremento en contenido de polifenoles y terpenoides en la planta (Qingwen et al., 1998).

Al control biológico de insectos por $P$. putida 89B-27, Serratia marcescens 90-166, Flavomonas oryzihabitans INR-5 y Bacillus pumilus INR-7 ejerce una reducción significativa en poblaciones de los escarabajos rayado Acalyma vittatum y el escarabajo manchado Diabrotica undecimpunctata howardi en el cultivo del pepino (Zehnder et al., 1997).

Estrategias actuales de manejo de nemátodos-plagas

Las labores culturales para el control de nematodos plagas en plantaciones agrícolas el método más eficaz es el arranque y extirpación de raíces que pueden servir de reservorio del patógeno (Rasky et al., 1965). Otros métodos para el control de nematodos se basan en la aplicación de calor húmedo (solarización) y calor seco (quema de hojarasca y otros restos vegetales), se consideran pocos efectivos debido a que penetran solo unos pocos centímetros.

A rasgos globales, se agrupan las estrategias de nematicidas en suelos cultivables:

a) Nematicidas. Se usan en promedio dos veces al año a las dosis recomendadas por el fabricante. Tanto los carbamatos (Carbofuran y Oxamil) como los organofosforados (Terbufos, Etroproph, Fenamiphos, Cadusafos) son inhibidores de las acetilcolinesterasas del nemátodo, dependiendo de la dosis y la concentración pueden actuar como nematóxicos (matan los nematodos) o nematostáticos (inhiben su funcionamiento normal). El bromuro de metilo (BrM) es el producto químico más empleado para el control de nematodos. BrM es extremadamente tóxico y provoca el agotamiento de la capa de Ozono (clasificación de la OMS: grupo 1A) (Van den Oever et al., 1982; Molina, 2007).

Una de las principales limitantes del empleo de agroquímicos es que su aplicación frecuente modifica la microflora y microfauna del suelo alterando las cadenas tróficas, eliminando microorganismos antagonistas de los nematodos fitoparásitos (Araya, 2004). También su efectividad no ha sido la esperada, por ejemplo, Valenzuela et al. (1992) evaluaron la aplicación de tres nematicidas (carbofuran, fenamiphos y ethoprop) durante tres años en diversas zonas de cultivo de vid 'Thompson Seedless', no generaron efecto sobre la población de $X$. index (se mantuvo constante de 200350 ejemplares / $250 \mathrm{~cm}^{3}$ de suelo). b) Control biológico. Las bacterias endofíticas forman parte de la gran cantidad de bacterias benéficas presentes en la rizósfera, que favorecen el crecimiento y desarrollo de las plantas y las protegen contra otros organismos del suelo que causan enfermedades (Hallmann et al., 1997). La aplicación de este tipo de rizobacterias en diversos cultivos ha dado como resultado la promoción del crecimiento de las plantas, observándose un incremento en el número de brotes, vigor, producción de biomasa y desarrollo del sistema radicular (Kloepper et al., 1999).

\section{Aplicación de PGPR como biocontroladores frente a nemátodos-plagas}

A pesar de los intentos de utilizar PGPR para el control de nematodos estos se han visto limitados. El empleo de agentes controladores biológicos de nematodos parasíticos en plantas, ha sido reportado como una estrategia exitosa para su biocontrol (Sikora, 1992). P. fluorescens induce la resistencia sistémica e inhibe la penetración de la raíz por el nemátodo del quiste Heterodera schachitii, en la remolacha azucarera (Oostendorp and Sikora, 1989). De igual forma, $B$. subtilis induce la protección contra $M$. incognita y $M$. arenaria en algodón (Sikora, 1988).

En el control biológico de nematodos, las cepas de $P$. fluorescens y $P$. putida han demostrado una fuerte actividad antagonista contra los nematodos Radopholus similis y Meloidogyne spp., en banano, maíz y tomate (Aalten et al., 1998). Un aislamiento endofítico de $P$. aeruginosa produjo compuestos tóxicos in vitro que resultó con alta mortalidad de los estadios juveniles de $M$. javanica (Siddiqui y Ehteshamul-Haque, 2001). El compuesto 2,4-DAPG producido por $P$. fluorescens CHAO reduce la eclosión de huevos de $M$. javanica (Siddiqui y Shaukat, 2003). La aplicación de $P$. fluorescens CHAO y la producción de la proteasa AprA, contribuye directa o indirectamente al biocontrol de $M$. incognita, reduciendo la eclosión de huevos e induciendo la mortalidad de nematodos juveniles durante la infección de raíces en tomate y soya (Siddiqui et al., 2005).

Para mejorar la eficacia del control biológico por Pseudomonas fluorescens CHA0 se ha procedido a modificar genéticamente (GM), esta cepa se le añadió un plásmido CHA0/pME342, responsable en la sobreproducción de los antibióticos: 2,4-DAPG, Plt y la adición de molibdato de amonio (NH4-Mo) para el control de M. javanica (Hamid et al., 2003). El efecto de la cepa EPS291 y EPS817 de P. fluorescens, mejora el crecimiento y nutrición del banano incrementando su longitud, diámetro, área foliar y peso fresco de raíz, así como la reducción de un $48 \%$ al número de huevos de M. javanica y nematodos juveniles por gramo de raíz (Rodríguez et al., 2008). 
Para el control biológico de nematodos se está recurriendo a la combinación de hongos antagonistas y PGPR producidos por bacterias como: Azotobacter chroococcum, Bacillus subtilis y Pseudomonas putida. La combinación de estos microrganismos y su inoculación en raíces de tomate, en suelos que contienen como sustrato estiércol de ganado, obtienen un incremento del $79 \%$ de la reducción del agallamiento por M. incognita (Siddiqui y Futai, 2009). La combinación de Trichoderma harzianum y $P$. fluorescens $\mathrm{CHA} 0$ proporciona una mejora en la producción de componentes nematicidas para el control de M. javanica en tomate, demostrando que la combinación de estos dos micro-organismos aumentan la mortalidad de nematodos juveniles en un $64 \%$, siendo esto considerado su aplicación en un mix-compatible y más cercano a la situación natural, esto mejora la eficacia y fiabilidad del control biológico (Siddiqui y Shaukat, 2004).

El impacto diferencial de algunas especies de hongos del género Aspergillus y su combinación con P. fluorescens CHA0 para el biocontrol de $M$. javanica en Lycopersicum esculentum (tomate), da diferentes resultados: $A$. niger solo o combinado con la bacteria inhibe el agallamiento causado por el nematodo, a diferencia de $A$. quadrilineatus solo o combinado con $P$. fluorescens $\mathrm{CHA} 0$ no reduce la presencia del nematodo. Esto demuestra claramente que la producción de nematicidas varía según las especies de hongo con que se desarrolla conjuntamente con la bacteria. A. niger mejora la producción de componentes nematicidas por $P$. fluorescens in vitro y proporciona un potencial biocontrol de la bacteria cuando es inoculada en tomate (Siddiqui et al., 2004).

La producción de ácido fenilacético por el hongo patogénico Rhizoctonia solani reprime la biosíntesis de componentes nematicidas en condiciones in vitro y la influencia del biocontrol de P. fluorescens CHA0 para causar la muerte y supresión del nematodo $M$. incognita (Siddiqui y Shaukat, 2005).

\section{Conclusiones}

$\mathrm{E}$ 1 mecanismo de defensa en especies agrícolas está liderado por las barreras físicas que dificultan el ingreso de los hongos patogénicos. Al romper estas barreras, se activa una respuesta química que acelera la producción de enzimas y proteínas de reconocimiento específico e inespecífico.

El empleo de las PGPR, están colaborando en el control biológico mediante la producción de metabolitos secundarios, que ejercen un efecto antagonista o quimiostático hacia hongos, bacterias e insectos plagas. El antibiótico más abordado es el 2,4-DAPG que mantiene un efecto antagonista a un sinnúmero de problemas fitopatológicos, siendo P. fluorescens CHA0 la productora del antibiótico.

Las células de las plantas expresan una amplia red de señalizaciones, que se manifiestan como mecanismo de defensa antes y después de ser expuestas a un agente patogénico. RSA se debe a la acumulación de ácido salicílico (AS) que permiten la regulación e interacción con numerosas moléculas y hormonas que estimulan los mecanismos de defensa en la planta, con la producción de proteínas relacionadas a patógenos PR. Además, que darían paso a la producción de $\mathrm{RH}$, esto se manifiesta con la muerte celular en las plantas, ejerciendo la protección para hongos biotrofos.

De forma contraria la producción de AS por SAR, tiene una forma antagónica con el ET y JA, reprimiendo la expresión de genes por estas vías de activación. La RSI por activación de bacterias no patógenas PGPR, induce a la producción de fitohormonas etileno (ET) y ácido jasmónico (JA), que mantienen un estado de imprimación a la planta con el objetivo de responder de forma oportuna al ataque de un agente patógeno. Sin embargo, ambas respuestas están entrelazadas molecularmente, lo cual está demostrado por su dependencia en una versión funcional del gen NPR1 en Arabidopsis thaliana.

Es de importancia recabar información, para entender en detalle los mecanismos implicados en SAR, y el empleo de las PGPR que estimulan ISR. Esto permitirá obtener conocimientos para mejorar los cultivos agrícolas y su producción de manera amigable con el ambiente. En la actualidad el empleo de pesticidas para el control de hongos, bacterias y nematodos, ha originado un creciente deterioro del ecosistema, teniendo como consecuencia que las frutas producidas bajo este régimen posean un alto grado de contaminación. Frente a este problema es necesario incorporar nuevas tecnologías que permitan dar paso a la utilización de productos de origen ecológico y disminuyan así la utilización de productos químicos para el control de los mismos.

\section{Bibliografía}

Aalten, P., Vitour, D., Blanvillain, D., Gowen, S., Sutra. L. 1998. Effect of Rhizosphere fluorescent Pseudomonas strains on plant-parasitic nematodes Radopholus similis and Meloidogyne spp. Letters in Applied Microbiology 27: 357-361.

Araya, M. 2004. Situación actual del manejo de nematodos en banano (Musa AAA) y plátano (Musa AAB) en el trópico americano. Montpelier, 
FR. INIBAP. 79-102.

Atlas, R. 2002. Ecología Microbiana y microbiología ambiental. Pearson Educación. Madrid. 67.

Bent, A., Mackey, D. 2007. Elicitors, effectors, and R genes: the new paradigm and a lifetime supply of questions. Annual Review of Phytopathology 45: 399-436.

Bong, J., Sikorowski, P. 1991. Efects of cytoplasmic polyhedrosis virus and bacterial contamination on growth and development of the corn earworm, Helicoverpa zea. Journal Invertebrate Pathology 57: 406-412.

Conejero, V. 1996. La respuesta defensiva de las plantas y su posible manipulación biotecnológica. En Biotecnología y Agricultura. Fundación Bancaixa.

Conejero, V. 1997. Biotecnología y Agricultura: Las plantas del futuro. Fundación Bancaixa. 97-119.

Conrath, U., Beckers, V., Flors, P., Garcia-Agustin, G., Jakab, F., Mauch, M., Newman, C., Pieterse, M., Poinssot, B., Pozo, M., Pugin, A., Schaffrath, U., Ton, J., Wendehenne, D., Zimmerli, L., Mauch, B. 2006. Priming: getting ready for battle. Molecular Plant-Microbe Interactions 19: 1062-1071.

Cook, J., Baker, K. 1989. The nature and practice of biological control of plant pathogens. 2nd Ed. The American Phytopathological Society USA. 539.

Das, S., De Mason, D., Ehlers, J., Close, T., Philip, C. 2008. Histological characterization of root-knot nematode resistance in cowpea and its relation to reactive oxygen species modulation. Journal of Experimental Botany 21: 1-9.

Desender, S., Andrivon, D., Val, F. 2007. Activation of defence reactions in Solanaceae: where is the specificity. Cellular Microbiology 9: 21-30.

Devoto, A., Ellis, C., Magusin, A., Chang, H., Chilcott, C., Zhu, T., Turner, J. 2005. Expression profiling reveals COI1 to bea key regulator of genes involved in wound- and methyl jasmonate-induced secondary metabolism, defence, and hormone interactions. Plant Mol Biol. Jul; 58: 497-513.

Dwivedi, D., Johri, B. 2003. Antifungal from fluorescent pseudomonads: Biosynthesis and regulation. Currente Science 85: 1693-1703.

Ebel, J., Cosio, E. 1994. Elicitors of plant defense responses. International Review Cytology 148: $1-36$.

Fukui, R., Poinar, E., Bauer, P., Schroth, M., Hendson, M., Wang, X., Hancock, J. 1994. Spatial colonization patterns and interaction of bacteria on inoculated sugar beet seed. Phytopathology 84 : 1338-1345.

Gaffney, T., Friedrich, L., Vernooij, B., Negrotto, D., Nye, G., Uknes, S., Ward, E., Kessmann, H., Ryals, J. 1993. Requirement of salicylic acid for the induction of systemic acquired resistance. Science 261: 754-756.

Haas, D., Défago, G. 2005. Biological control of soilborne pathogens by fluorescent pseudomonads. Nature Reviews Microbiology 3: 307-319.

Hallmann, J., Berg, G. 2006. Spectrum and population dynamics of bacterial root endophytes, Microbial root endophytes. Springer-Verlag, 15-32.

Hallmann, J., Quadt-Hallmann, A., Mahaffee, W., Kloepper, J. 1997. Bacterial endophytes in agricultural crops. Canadian Journal of Microbiology 43:895-914.

Hamid, M., Siddiqui, I. Shaukat. S. 2003. Improvement of Pseudomonas fluorescens CHA0 biocontrol activity against root-knot nematode by the addition of ammonium molybdate. Letters in Applied Microbiology, 36: 239-244.

Hammond-Kosack, K., Jones, J. 1996. Resistance gene dependent plant defense responses, The Plant Cell 8: 1773-1791.

Heeb, S., Haas, D. 2001. Regulatory roles of the GacS/ GacA two-component system in plant-associated and other Gram negative bacteria. Mol Plant Microbe Interact 14: 1351-1363.

Iavicoli, A., Boutet, Eñ., Buchala, A., Metraux, J. 2003. Induced systemic resistance in Arabidopsis thaliana in response to root inoculation with Pseudomonas fluorescens CHA0. Molecular Plant Microbe Interactions 16: 851-858.

Jackson, O., Taylor, C. 1996. Plant-microbe interactions: Life and death at the interface. Plant Cell, 8: 16511668.

Jones, J. y Dangl, J. 2006. The plant immune system. Nature 444: 323-329.

Kloepper, J., Rodríguez, R., Zehnder, G., Murphy, J., Sikora, E., Fernández, C. 1999. Plant root-bacterial interactions in biological control of soilborne diseases and potential extension to systemic and foliar diseases. Australasian Plant Pathology 28: 21-26.

Mackey, D., McFall, A. 2006. MAMPs and MIMPs: proposed classifications for inducers of innate immunity. Molecular Microbiology 61: 13651371.

Martin, G., Bogdanove, A., Sessa, G. 2003. Understanding the functions of plant disease resistance proteins. Annual Review of Plant Biology 54: 23-61.

Mauch-Mani, B., Slusarenko, A. 1993. Arabidopsis as a model host for studying plant-pathogen interactions. Trends Microbiology 7: 265-70.

Maurhofer, M., Hase, C., Meuwly, P., Metraux, J., Defago, G. 1994. Induction of systemic resistance of tobacco to tobacco necrosis virus by the root- 
colonizing Pseudomonas fluorescens strain CHA0: influence of the gacA gene and of pyoverdine production. Phytopathology 84: 139-146.

Métraux, J., Signer, H., Ryals, J., Ward, E., Wyssbenz, M., Gaudin, J., Raschdorf, K., Schmid, E., Blum, W., Inverardi, B. 1990. Increase in salicylic acid at the onset of systemic acquired resistance in cucumber. Science 250: 1004-1006.

Molina, L. 2007. Bromuro de metilo, breve descripción de su toxicología como fundamento para la vigilancia de salud ocupacional. Departamento de Salud Ocupacional, Instituto de Salud Pública de Chile. Disponible www.cienciaytrabajo.cl

Moreno, A. 2006. Aplicaciones biotecnológicas del gen afp (Antifungal Protein) de Aspergillus giganteus para la protección de plantas frente a infección por patógenos. Trabajo de tesis doctoral realizado en el IBMB-CSIC de Barcelona 106.

Nimchuk, Z., Eulgem, T. Holt, B., Dangl, J. 2003. Recognition and response in the plant immune system, Annual Review Genetics 37: 579-609.

Nurnberger, T., Scheel, D. 2001. Signal transmission in the plant immune response. Trends in Plant Science 6: 372-379.

Oostendorp, M., Sikora, R. 1989. Seed-treatment with antagonistic rhizobacteria for the suppression of Heterodera schachtii early root infection of sugar beet. Review Nematology 12: 77-83.

Pieterse, C., Van Loon, L. 1999. Salicylic acidindependent plant defense pathways, Trends in Plant Science, 22: 291-296.

Pieterse, C., Van Wees, S., Van Pelt, J., Knoester, M., Laan, R., Gerrits, H., Weisbeek, P., Van Loon, P. 1999. A novel signaling pathway controlling induced systemic resistance in Arabidopsis, The Plant Cell 10: 1571-1580.

Preston, M. 2004. Plant perceptions of plant growthpromoting Pseudomonas, Philosophical Transaction of the Royal Society 359: 907-918.

Qingwen, Z., Ping, L., Gang, W., Qingnian, C. 1998. On the biochemical mechanism of induced resistance of cotton to cotton bollworm by cutting off young seedling at plumular axis, Acta Phytophylacica Sinica 25: 209-212.

Raaijmakers, J., Weller, M., Thomashow, S. 1997. Frequency of antibiotic-producing Pseudomonas spp, in natural environments, Applied and Environmental Microbiolog, 63: 881-887.

Ramamoorthy, V., Raguchander, T., Samiyappan, R. 2002. Induction of defense-related proteins in tomato roots treated with Pseudomonas fluorescens Pf1 and Fusarium oxysporum f, sp, Lycopersici, Plant and Soil 239: 55-68.

Rasky, D., Hewitt, W., Goheen, A., Taylor, C., Taylor,
R. 1965. Survival of Xiphinema index and reservoirs of fanleaf virus in fallowed Vineyard Soil, Nematologica 11: 349-352.

Rodríguez, D., Sardanelli, M., Ruíz, J. 2007. Attachment of bacteria to the roots of higher plants. FEMS Microbiology Letters 272: 127-136.

Ryals, J., Neuenschwander, U., Willits, M., Molina, A., Steiner, H., Hunt, M. 1996. Systemic Acquired Resistance. Plant Cell 8: 1809-1819.

Sacherer, P., Défago, G., Haas, D. 1994. Extracellular protease and phospholipase $\mathrm{C}$ are controlled by the global regulator gene gacA in the biocontrol strain Pseudomonas fluorescens CHA0. FEMS Microbiology Letters 116: 155-160.

Siddiqui, I., Ehteshamul-Haque, S. 2001. Suppression of the root rot-root knot disease complex by Pseudomonas aeruginosa in tomato: the influence of inoculum density, nematode populations, moisture and other plant-associated bacteria. Plant Soil 237: 81-89.

Siddiqui, I., Haas, D., Heeb, S. 2005. Extracellular protease of Pseudomonas fluorescens CHA0, a biocontrol factor with activity against the rootknot nematode Meloidogyne incognita. American Society for Microbiology 71: 5646-5649.

Siddiqui, I., Shaukat, S. 2003. Suppression of rootknot disease by Pseudomonas fluorescens CHA0 in tomato: importance of bacterial secondary metabolite, 2,4-diacetylphloroglucinol. Soil Biology and Biochemistry 35: 1615-1623.

Siddiqui, I., Shaukat, S. 2004. Trichoderma harzianum enhances the production of nematicidal compounds in vitro and improves biocontrol of Meloidogyne javanica by Pseudomonas fluorescens in tomato. The Society for Applied Microbiology, 38: 169175.

Siddiqui, I., Shaukat, S. 2005. Phenylacetic acidproducing Rhizoctonia solani represses the biosynthesis of nematicidal compounds in vitro and influences biocontrol of Meloidogyne incognita in tomato by Pseudomonas fluorescens strain CHA0 and its GM derivatives. Journal of Applied Microbiology 98: 43-55.

Siddiqui, I., Shaukat, S., Khan, A. 2004. Differential impact of some Aspergillus species on Meloidogyne javanica biocontrol by Pseudomonas fluorescens strain CHA0. The Society for Applied Microbiology 39:74-83.

Siddiqui, Z., Futaid, K. 2009. Biocontrol of Melodogyne incognita on tomato using antagonistic fungi, plantgrowth-promoting rhizobacteria and cattle manure. Society of Chemical Industry 65: 943-948.

Sikora, A. 1988. Interrelationship between plant health promoting rhizobacteria, plant parasitic nematodes 
and soil microorganisms, Mededelingen Faculteit Landbouwwetenschappen Rijksuniversiteit Gent 53: $867-878$.

Sikora, A. 1992. Management of the antagonistic potential in agricultural ecosystems for the biological control of plant parasitic nematodes. Annual Review Phytopathology 30: 245-270.

Somers, E., Vanderleyden, J. and Srinivasan, M. 2004. Rhizosphere bacterial signalling: a love parade beneath our feet. Annual Review Microbiology 30: 205-240.

Sticher, L., Mauch-Mani, B. and Métraux, J. 1997. Systemic acquired resistance. Annual Reviews Phytopathology 35: 235-270.

Ton, J., Van Pelt, J., Van Loon, L., Pieterse, C. 2002. Differential effectiveness of salicylate-dependent and jasmonate/ethylene-dependent induced resistance in Arabidopsis. Molecular PlantMicrobe Interactions 15: 27-34.

Trouvelot, S., Varnier, A., Allègre, A., Mercier, L., Baillieul, F., Arnould, C., Gianinazzi-Pearson, V., Klarzynski, O., Joubert, M., Pugin, A., Daire, X. 2008. A $\beta-1.3$ glucan sulfate induces resistance in grapevine against Plasmopara viticola through priming of defense responses, including HR-like cell death. Molecular Plant-Microbe Interactions 21: 232-243.

Valenzuela, A., Aballay, E., Torres, M. 1992. Identificación y frecuencia de nematodos asociados a la vid en la Región Metropolitana, Chile. Investigación Agrícola (Chile), 12: 15-17.

Vallad, G., Goodman, R. 2004. Systemic Acquired Resistance and Induced Systemic Resistance in Conventional Agriculture, Review \& Interpretation. Published in Crop Science Society of America 44: 1920-1934.

Van den Oever, R., Roosels, D., Lahaye, D. 1982. Actual hazard of methyl bromide fumigation in soil desinfection. British Journal of Industrial Medicin, 39: 140-144.

Van der Ent, S., Van Hulten, M., Pozo, M., Czechowski, T., Udvardi, M., Pieterse, C., Ton, J. 2009. Priming of plant innate immunity by rhizobacteria and $\beta$-aminobutyric acid: differences and similarities in regulation, New Phytologist 183: 419-431.
Van Loon, L., Bakker, A., Pieterse, C. 1998. Systemic resistance induced by rhizosphere bacteria. Annual Review Phytopathology 36: 453-483.

Van Peer, R., Niemann, J., Schippers, B. 1991. Induced resistance and phytoalexin accumulation in biological control of Fusarium wilt of carnation by Pseudomonas sp strain WCS 417r. Phytopathology 81: 728-734.

Verhagen, B., Glazebrook, J., Zhu, T., Chang, H., van Loon, L., Pieterse, C. 2004. The transcriptome of rhizobacteria-induced systemic resistance in Arabidopsis. Molecular Plant Microbe Interactions. 17: 895-908.

Verhagen, B., Trotel, P., Couderchet, M., Hofte, M., Aziz, A. 2009. Pseudomonas spp, induced systemic resistance to Botrytis cinerea is associated with induction and priming of defence responses in grapevine. Journal of Experimental Botany 12: $1-12$.

Vidhyasekaran, P., Muthamilan, M. 1999. Evaluation of powder formulation of Pseudomonas fluorescens Pf1 for control of rice sheath blight. Biocontrol Science and Technology 9: 67-74.

Wei, G., Kloepper, W., Tuzun, S. 1991. Induction of systemic resistance of cucumber to Colletotrichum orbiculare by select strains of plant growth promoting rhizobacteria. Phytopathology 81: 1508-1512.

Williamson, V. 1999. Plant nematode resistance genes. Current Opinion in Plant Biology 2: 327-331.

Zehnder, G., Kloepper, J., Yao, C., Wei, G. 1997. Induction of systemic resistance in cucumber against cucumber beetles (Coleoptera: Chrysomelidae) by plant growth-promoting rhizobacteria. Biological and Microbial Control 90: 391-396.

Zinovèva, S., Perekhod, E., IIina, A., Udalova, Z., Gerasimova, N., Vasyukova, N., Ozeretskovskaya, O., Sonin, M. 2001. PR proteins in plants infested with the root-knot nematode Meloidogyne incognita. Doklady Biological Sciences 379: 393395. 